Discussion Paper No. 745

\title{
INPUT SPECIFICITY AND PRODUCT DIFFERENTIATION
}

\author{
Noriaki Matsushima \\ and \\ Tomomichi Mizuno
}

June 2009

The Institute of Social and Economic Research Osaka University

6-1 Mihogaoka, Ibaraki, Osaka 567-0047, Japan 


\title{
Input specificity and product differentiation*
}

\author{
Noriaki Matsushima $^{\dagger}$ \\ Institute of Social and Economic Research, Osaka University \\ Tomomichi Mizuno \\ Competition Policy Research Center, Japan Fair Trade Commission
}

June 17, 2009

\begin{abstract}
Using a simple product differentiation model with elastic demands, we investigate the relationship between differentiation strategies and vertical relations. Depending on the competitive structure in the upstream market, three differentiation patterns (maximum, minimum and partial differentiation) can appear in equilibrium even though each downstream firm freely determines the degree of product differentiation. When downstream firms must incur positive investment costs to differentiate their products, they tend to do so if the upstream market is competitive.
\end{abstract}

\section{JEL classification numbers: L13.}

Key words: oligopoly, product differentiation, upstream firm, input specificity

\footnotetext{
*We would like to thank Masamichi Kawano, Toshihiro Matsumura, Keizo Mizuno, Dan Sasaki and the seminar participants at Kwansei Gakuin University and the Applied Economics Workshop (Tohoku University) for their helpful comments. The first author gratefully acknowledges financial support from a Grant-in-Aid for Encouragement of Young Scientists from the Japanese Ministry of Education, Science and Culture. Needless to say, we are responsible for any remaining errors. The views expressed herein are those of the authors and should not be interpreted as those of the Japan Fair Trade Commission.

${ }^{\dagger}$ Corresponding author: Noriaki Matsushima, Institute of Social and Economic Research, Osaka University, Mihogaoka 6-1, Ibaraki, Osaka 567-0047, Japan. Phone: +81-6-6877-1111 (Ex. 9170). E-mail: nmatsush@iser.osaka-u.ac.jp
} 


\section{Introduction}

Manufacturers often have relationships with many input suppliers. For instance, in the aircraft industry, the jet (turboprop) engine and aircraft industries are vertically related. To produce a differentiated product, aircraft firms must procure suitable but costly equipment. Engine companies also have relations with many buyers, and potentially with all of them (Bonaccorsi and Giuri (2001)). In the automobile industry, Toyota procures electric parts from many input suppliers, including Denso, which is one of the largest auto part manufacturers. ${ }^{1}$ Denso sometimes supplies other automobile manufacturers, for instance Daimler Chrysler. Thus, its electrical parts may be used in automobiles from different manufacturers.

When manufacturers produce (horizontally) differentiated products, they sometimes face constraints that stem from the technological capacities of suppliers. When those manufacturers are able to negotiate with many suppliers of suitable inputs, they can procure those inputs at reasonable prices. In contrast, when there are only a few suppliers of suitable inputs, the manufacturers must pay higher prices. That is, competitiveness in input markets affects the procurement conditions of manufacturers.

Because decisions on product positioning (differentiation), which is an important strategic tool of firms, are influenced by such buyer-supplier relationships, ${ }^{2}$ some researchers investigate the relationship between differentiation strategies and vertical relations. Using Hotelling location models, Brekke and Straume (2004) and Matsushima (2004, 2008) discuss how upstream units affect the differentiation strategies of downstream firms. ${ }^{3}$ In Brekke and Straume (2004), firms acquire inputs through bilateral monopoly relations with suppliers. They show

\footnotetext{
${ }^{1}$ Ahmadjian and Lincoln (2001) research the vertical relationship between Toyota and Denso.

${ }^{2}$ There are many studies on product positioning decisions. See, for instance, Hotelling (1929), d'Aspremont et al. (1979), Hauser and Shugan (1983), Vandenbosch and Weinberg (1995), and Sayman, Hoch, and Raju (2002).

${ }^{3}$ Bárcena-Ruiz and Casado-Izaga (2008) incorporate the sequential move of upstream prices (wages) into the model of Brekke and Straume (2004). Using a Hotelling location model, Erkal (2007) also investigates how the buyer-supplier relationship affects differentiation strategies.
} 
that the existence of upstream suppliers enhances the degree of product differentiation. In Matsushima (2004, 2008), each upstream firm that locates in a linear city engages in price competition for the business of downstream firms. To supply one unit of input to a downstream firm, each upstream firm incurs a transport cost quadratic in distance. These papers show that the degree of product differentiation decreases as the coefficient of the quadratic transport cost incurred by each upstream firm increases. Although the settings of Brekke and Straume (2004) and Matsushima (2004, 2008) are only slightly different, those papers provide quite different results.

Although those researchers provide interesting insights into the relationship between differentiation strategies and vertical relations, they only consider markets in which downstream firms compete in price (strategic complement). Moreover, consumer demand is inelastic in their models because they use Hotelling models. It is not obvious how vertical relations affect the differentiation strategies of downstream firms when such firms compete in quantity (strategic substitute). The aim of this paper is to investigate this problem. Moreover, a further contribution of this paper is that our model succeeds in merging the previous three papers into a simple duopoly model with elastic demand functions.

The model setting of the paper is as follows. There are two upstream and two downstream firms. Each downstream firm produces a differentiated final product, and must buy an input from the upstream firms. Each downstream firm determines the degree of product differentiation (denoted by $\gamma$ ). Each firm must incur investment costs to differentiate its product (product R\&D). We consider two cases concerning the competitive environment of upstream firms. First, each upstream firm has a bilateral monopoly relation with its buyer (a downstream firm). Second, each upstream firm faces competitive forces that can potentially deprive it of its trade with its downstream partner. To supply one unit of input to a downstream firm, the potential suppliers must incur two additional marginal costs $\left(k+\tau d_{i}\right)$ that depend on the degree of product $\mathrm{R} \& \mathrm{D}$ that the downstream firm undertakes $\left(d_{i} \in[0,1 / 2]\right.$, 
$1-d_{1}-d_{2}=\gamma$ ), where $k$ and $\tau$ are positive constants. We can interpret the additional costs of potential suppliers as being the conversion cost from the product of the upstream firm into an input suitable for the downstream firm. After purchasing its input from an upstream firm, each downstream firm sets the quantity to be supplied.

We show that when the investment cost for product $R \& D$ is zero, maximum differentiation appears in equilibrium if $k$ is large or $\tau$ is small. If $k$ is small and $\tau$ is large, minimum differentiation appears. If $k$ has an intermediate value and $\tau$ is large, only one downstream firm engages in product $\mathrm{R} \& \mathrm{D}$. We also show that both minimum and maximum differentiation appear in equilibrium if $k$ is small and $\tau$ has an intermediate value. Moreover, we show that when the investment cost for product $\mathrm{R} \& \mathrm{D}$ is positive, minimum differentiation tends to appear in equilibrium if each upstream firm has a bilateral monopoly relation with its buyer (a downstream firm). A slight difference in product R\&D technologies leads to quite different equilibrium outcomes in product differentiation. Those results are somewhat different from Brekke and Straume (2004) and Matsushima (2004, 2008), and provide additional insights into the discussion of the relationship between product differentiation and vertical relations.

The setting and the results of this paper are related to the case of the aircraft industry. ${ }^{4}$ There are two major firms in this industry, Airbus and Boeing. Those firms rely heavily on firm-specific inputs (engines, wings, horizontal stabilizers) produced by independent manufacturers. For instance, Rolls Royce and CFM International (a joint venture between GE and the French company Snecma) make highly specific turbofan engines for airplanes. Rolls Royce made the Trent XWB turbofan engine to meet the specific requirements of the Airbus A350 XWB family, and developed the Trent 900 series exclusively to power the new Airbus A380. Furthermore, CFM International designed the CFM56-3 turbofan engine exclusively for Boeing aircraft. ${ }^{5}$ Under the procurement condition, Airbus and Boeing have considered

\footnotetext{
4 This paragraph is based on the discussions in Beelaerts van Blokland et al. (2008), Nalebuff (2002), Esty and Ghemawat (2002), and Tombak (2006).

${ }^{5}$ In reality, these engine manufacturers sometimes supply both Airbus and Boeing if possible.
} 
whether their products should be differentiated. At one time, Airbus and Boeing produced highly differentiated aircraft (A380 and Boeing 787), however at other times, they produced less-differentiated aircraft (the A340 and Boeing 747(777)) and competed directly. ${ }^{6}$ From this real world example, we can say that the technological constraints of input suppliers crucially affect the differentiation strategies of the two aircraft firms.

This paper is closely related to that of Lin and Saggi (2002). Using linear demand functions with product differentiation, they discuss the relationship between process and product R\&D. ${ }^{7}$ We add vertical relations to their model, and our motivation is quite different from theirs. Our main concern is how the existence of upstream firms and competition between them affects the differentiation strategies of downstream firms. ${ }^{8}$

The paper proceeds as follows. The next section outlines the basic environment. Section 3 provides an analysis of the model. Section 4 discusses the relationship between vertical relations and differentiation strategies. Finally, Section 5 offers some concluding remarks.

\footnotetext{
${ }^{6}$ The A3XX (which was rechristened the A380) program was formally launched in December 2000. After that event, Boeing abandoned the Sonic Cruise development program and launched the 787 program because of concerns about fuel efficiency in the ailing airline industry in 2002. Therefore, the A380 and Boeing 787 are highly differentiated. In 1987, Airbus launched the A330 and A340 airframes, which were designed to compete with the Boeing 747 on medium- to long-distance routes. Boeing then postponed the $7 \mathrm{~J} 7$ project to develop a short-range 150-seat aircraft (which has the potential to differentiate its product line from that of the large-scale intercontinental commercial jet market) and then developed the 777 airframe with technological features, seating capacity and range similar to those of the A340.

${ }^{7}$ Most subsequent studies of Lin and Saggi (2002) also focus on the complementarity of process and product $\mathrm{R} \& \mathrm{D}$, which is not the focus of this paper. See, for instance, Mantovani (2006) and Braun (2008).

${ }^{8}$ There are discussions on how vertical structure affects incentives of upstream and/or downstream firms for innovative activities. Given vertical market structures and competition environments, Ishii (2004) and Milliou (2004) discuss spillover effects of R\&D investments. Banerjee and Lin (2003), Brocas (2003), and Buehler and Schmutzler (2008) focus on the relation of vertical market structure and cost-reducing investment in oligopoly. These papers do not discuss how the existence of upstream firms affects the differentiation strategies of downstream firms. Pepall and Norman (2001) also consider vertical relationships and product differentiation. They consider vertical mergers and vertical foreclosure, but not endogenous product differentiation. In their model, the degree of product differentiation of the downstream firms is exogenous.
} 


\section{The model}

We consider a market with two downstream and two upstream firms. There is only one factor of production, which we refer to as the input. Each firm produces a differentiated final good in a constant-returns-to-scale process where one unit of the input becomes one unit of the final good. Each downstream firm can perform this conversion at no cost.

We assume that the two downstream firms compete in quantity. Now let $x_{i}$ denote $i$ 's sales. The inverse demand function of firm $i$ is given by

$$
p_{i}=1-x_{i}-\gamma x_{j}, i=1,2, i \neq j \text {. }
$$

where $p_{i}$ is the price of the final good produced by $i$, and $\gamma(\in[0,1])$ indicates the degree of product differentiation between the products. The lower the value of $\gamma$, the higher the degree of product differentiation. The value of $\gamma$ is determined by each firm's investment in product $\mathrm{R} \& \mathrm{D}$, denoted by $d_{i}(i=1,2)$.

We consider the downstream firm's investments in product R\&D. Following the setting in Lin and Saggi (2002), ${ }^{9}$ we assume that the value of $\gamma$ is determined by each downstream firm's investment in product $\mathrm{R} \& \mathrm{D}$, denoted by $d_{i}(i=1,2)$. The extent of product differentiation is $\gamma=1-\left(d_{1}+d_{2}\right)$, and $0 \leq d_{i} \leq 1 / 2$. The cost of product $\mathrm{R} \& \mathrm{D}$ is given by $F\left(d_{i}\right), F^{\prime} \geq 0$, $F^{\prime \prime} \geq 0$.

Let $z_{i}$ denote the amount of input supplied by the supplier of firm $i$. Each input supplier sets a wholesale price $w_{i}$ to maximize its profit function (without loss of generality, we assume that the marginal cost is normalized to zero):

$$
\pi_{U i}=w_{i} z_{i}, i=1,2 .
$$

The fact that the input suppliers unilaterally set the wholesale prices implies that they possess full bargaining power.

\footnotetext{
${ }^{9}$ See also Braun (2008), Cellini and Lambertini (2002), Lambertini et al. (1998), Rosenkranz (2003), and Weiss (2003).
} 
In this paper, we consider two cases concerning the technologies of upstream firms:

1. Neither upstream firm faces a competitor.

2. Each upstream firm faces competitors that are potentially able to supply the downstream firms. If a competitor incurs a marginal cost, $f_{i}=\tau d_{i}+k$, it is able to supply input to downstream firm $i$, where $\tau$ and $k$ are positive constants, and $d_{i}$ is the level of product $\mathrm{R} \& \mathrm{D}$ engaged in by downstream firm $i(i=1,2)$.

In the first case, each upstream firm is in a monopoly position with respect to its trading partner, similar to the setting in Brekke and Straume (2004). In the second case, upstream firms face potentially harmful competitive forces, which include rival upstream firms supplying the downstream firm (that is, upstream firms $i$ and $j$ are potential competitors $(i=1,2, i \neq$ j)). For instance, as mentioned in the introduction, while Rolls Royce and CFM International supply highly specific turbofan engines exclusively to Airbus and Boeing, respectively, these engine suppliers are both potential suppliers of either Airbus or Boeing (in reality, these engine manufacturers sometimes supply both Airbus and Boeing). Following the setting in Matsushima $(2004,2008)$, we assume that the marginal cost $f_{i}$ is increasing in the degree of product $R \& D$, which is related to the degree of product differentiation. This case is a slightly modified version of Matsushima $(2004,2008){ }^{10}$

We can interpret the first case as a special case of the second one. When $k$ is sufficiently high, potential competitors do not dare to supply inputs to a downstream firm because the marginal cost is prohibitively high. Because the first case is technically simpler than the second, we show both cases separately.

To summarize, we model the game structure as follows.

1. Each downstream firm engages in product R\&D.

\footnotetext{
10 This setting is somewhat similar to that of Aiura and Sato (2008), who discuss the differentiation strategies of firms in a Hotelling model.
} 
2. Each upstream input supplier sets its wholesale price.

3. Given these prices, each firm simultaneously decides on a quantity to supply.

\section{Analysis}

\subsection{No potential supplier}

In this case, there is no potential competitor to the upstream firms. Upstream firm $i$ unilaterally offers its wholesale price $w_{i}(i=1,2)$ to downstream firm $i$.

The profits of downstream firms 1 and 2 are:

$$
\pi_{D 1} \equiv\left(1-x_{1}-\gamma x_{2}-w_{1}\right) x_{1}-F\left(d_{1}\right), \quad \pi_{D 2} \equiv\left(1-x_{2}-\gamma x_{1}-w_{2}\right) x_{2}-F\left(d_{2}\right) .
$$

The first-order conditions lead to:

$$
x_{1}=\frac{2-\gamma-2 w_{1}+\gamma w_{2}}{4-\gamma^{2}}, \quad x_{2}=\frac{2-\gamma-2 w_{2}+\gamma w_{1}}{4-\gamma^{2}} .
$$

The profits of the input suppliers are:

$$
\pi_{U 1}=\frac{w_{1}\left(2-\gamma-2 w_{1}+\gamma w_{2}\right)}{4-\gamma^{2}}, \quad \pi_{U 2}=\frac{w_{2}\left(2-\gamma-2 w_{2}+\gamma w_{1}\right)}{4-\gamma^{2}} .
$$

The first-order conditions lead to:

$$
w_{1}=w_{2}=\frac{2-\gamma}{4-\gamma}
$$

The equilibrium profits of the downstream and the upstream firms are:

$$
\pi_{D i}=\frac{4}{(4-\gamma)^{2}(2+\gamma)^{2}}-F\left(d_{i}\right) \quad(i=1,2), \quad \pi_{U 1}=\pi_{U 2}=\frac{2(2-\gamma)}{(4-\gamma)^{2}(2+\gamma)} .
$$

\subsection{Potential suppliers}

In this case, potential suppliers can supply inputs to both downstream firms. If $f_{i}=\tau d_{i}+k$ is insufficiently large, upstream firm $i$ faces the constraint that its wholesale price for downstream firm $i$ cannot exceed $f_{i}$ because other potential suppliers can undercut its wholesale price to 
downstream firm $i$. Therefore, when we consider the determination of wholesale prices, we must take into account the constraints.

The profits of downstream firms 1 and 2 are:

$$
\pi_{D 1}=\left(1-x_{1}-\gamma x_{2}-w_{1}\right) x_{1}-F\left(d_{1}\right), \quad \pi_{D 2}=\left(1-x_{2}-\gamma x_{1}-w_{2}\right) x_{2}-F\left(d_{2}\right)
$$

The first-order conditions lead to:

$$
x_{1}=\frac{2-\gamma-2 w_{1}+\gamma w_{2}}{4-\gamma^{2}}, \quad x_{2}=\frac{2-\gamma-2 w_{2}+\gamma w_{1}}{4-\gamma^{2}} .
$$

The profits of the input suppliers are:

$$
\begin{aligned}
& \pi_{U 1}=\frac{w_{1}\left(2-\gamma-2 w_{1}+\gamma w_{2}\right)}{4-\gamma^{2}}, \text { s.t. } w_{1} \leq f_{1}, \\
& \pi_{U 2}=\frac{w_{2}\left(2-\gamma-2 w_{2}+\gamma w_{2}\right)}{4-\gamma^{2}}, \quad \text { s.t. } w_{2} \leq f_{2} .
\end{aligned}
$$

Without loss of generality, we assume that $f_{1} \geq f_{2}$, that is, $d_{1} \geq d_{2}$. In other words, the effort of firm 1 in product $R \& D$ is more significant than that of firm 2 . The first-order conditions lead to:

$$
\begin{aligned}
& \begin{cases}w_{1}=k+\tau d_{1}, \quad w_{2}=k+\tau d_{2}, & \text { if } k \leq k_{1}, \\
w_{1}=\frac{2-\gamma+\gamma k+\gamma \tau d_{2}}{4}, \quad w_{2}=k+\tau d_{2}, & \text { if } k_{1}<k \leq k_{2}, \\
w_{1}=w_{2}=\frac{2-\gamma}{4-\gamma}, & \text { if } k_{2}<k,\end{cases} \\
& \text { where } k_{1} \equiv \frac{2-\gamma-\tau\left(4 d_{1}-\gamma d_{2}\right)}{4-\gamma}, \quad k_{2} \equiv \frac{2-\gamma-\tau(4-\gamma) d_{2}}{4-\gamma} .
\end{aligned}
$$


The equilibrium profits of the downstream and the upstream firms are:
(1) $\left\{\begin{array}{l}\pi_{D 1}=\frac{\left((2-\gamma)(1-k)-2 \tau d_{1}+\gamma \tau d_{2}\right)^{2}}{(2-\gamma)^{2}(2+\gamma)^{2}}-F\left(d_{1}\right), \\ \pi_{D 2}=\frac{\left((2-\gamma)(1-k)-2 \tau d_{2}+\gamma \tau d_{1}\right)^{2}}{(2-\gamma)^{2}(2+\gamma)^{2}}-F\left(d_{2}\right),\end{array} \quad\right.$ if $k \leq k_{1}$
(2)
$\left\{\begin{array}{l}\pi_{D 1}=\frac{\left(2-\gamma+\gamma k+\gamma \tau d_{2}\right)^{2}}{4(2-\gamma)^{2}(2+\gamma)^{2}}-F\left(d_{1}\right) \\ \pi_{D 2}=\frac{\left(\left(8-\gamma^{2}\right)(1-k)-2 \gamma-\left(8-\gamma^{2}\right) \tau d_{2}\right)^{2}}{16(2-\gamma)^{2}(2+\gamma)^{2}}-F\left(d_{2}\right)\end{array}\right.$
if $k_{1}<k \leq k_{2},(13)$
(3) $\left\{\begin{array}{l}\pi_{D 1}=\frac{4}{(4-\gamma)^{2}(2+\gamma)^{2}}-F\left(d_{1}\right), \\ \pi_{D 2}=\frac{4}{(4-\gamma)^{2}(2+\gamma)^{2}}-F\left(d_{2}\right),\end{array}\right.$
(1) $\left\{\begin{array}{l}\pi_{U 1}=\frac{\left(k+\tau d_{1}\right)\left((2-\gamma)(1-k)-2 \tau d_{1}+\gamma \tau d_{2}\right)}{(2-\gamma)(2+\gamma)}, \\ \pi_{U 2}=\frac{\left(k+\tau d_{2}\right)\left((2-\gamma)(1-k)-2 \tau d_{2}+\gamma \tau d_{1}\right)}{(2-\gamma)(2+\gamma)},\end{array} \quad\right.$ if $k \leq k_{1}$,
$(2)\left\{\begin{array}{l}\pi_{U 1}=\frac{\left(2-\gamma+\gamma k+\gamma \tau d_{2}\right)}{8(2-\gamma)(2+\gamma)} \\ \pi_{U 2}=\frac{\left(k+\tau d_{2}\right)\left(\left(8-\gamma^{2}\right)(1-k)-2 \gamma-\left(8-\gamma^{2}\right) \tau d_{2}\right)}{4(2-\gamma)(2+\gamma)}\end{array}\right.$ if $k_{2}<k$.
(3) $\left\{\begin{array}{l}\pi_{U 1}=\frac{2(2-\gamma)}{(4-\gamma)^{2}(2+\gamma)} \\ \pi_{U 2}=\frac{2(2-\gamma)}{(4-\gamma)^{2}(2+\gamma)}\end{array}\right.$

\section{Endogenous product differentiation}

We now discuss how each downstream firm determines its products positions.

\subsection{No investment cost $(F=0)$}

We now suppose that $F=0$ for any $d_{i}(i=1,2)$. Each downstream firm freely sets $\gamma=$ $1-d_{1}-d_{2}$ to maximize its own profit. We consider two cases: that with no competing potential supplier and that with potential suppliers. 


\subsubsection{No potential supplier}

Differentiating $\pi_{D i}$ with respect to $d_{i}$, we have:

$$
\frac{\partial \pi_{D 1}}{\partial d_{1}}=\frac{\partial \pi_{D 2}}{\partial d_{2}}=\frac{16\left(d_{1}+d_{2}\right)}{\left(3-d_{1}-d_{2}\right)^{3}\left(3+d_{1}+d_{2}\right)^{3}} \geq 0 .
$$

Therefore, each downstream firm chooses $d_{i}=1 / 2(i=1,2)$.

Proposition 1 When there is no potential competitor for either upstream firm, if $F=0$ for any $d_{i}(i=1,2), d_{1}=d_{2}=1 / 2$ in equilibrium.

\subsubsection{Potential suppliers}

To clarify the analysis, we now restrict the choices of the downstream firms. We tentatively assume that each downstream firm has only two options, $d_{i}=0$ and $d_{i}=1 / 2(i=1,2)$. Because of the simplification, the game is reduced to a simple $2 \times 2$ matrix. In the main text, we only solve the $2 \times 2$ matrix. Fortunately, we can show that the equilibrium outcomes derived by the $2 \times 2$ matrix really appear as equilibrium outcomes in the game in which each downstream firm freely sets $d_{i} \in[0,1 / 2](i=1,2) .{ }^{11}$ Roughly speaking, in this setting, the profit functions of the downstream firms are convex with respect to $d_{i}$. Therefore, the boundaries, $d_{i}=0$ and $d_{i}=1 / 2$, may be the best candidates.

There are three cases, depending on the endogenous and exogenous variables: $(1) k \leq k_{1}$, (2) $k_{1}<k \leq k_{2}$, and (3) $k_{2}<k$ (see equation (12)). When each firm chooses $d_{i}=0$ $(i=1,2)$, that is, $\gamma=1$, the first case appears if $k \leq 1 / 3$ and the third case appears if $1 / 3<k$. When one downstream firm chooses $d_{i}=0$ and another chooses $d_{j}=1 / 2(i=1,2$, $i \neq j)$, that is, $\gamma=1 / 2$, the first case appears if $k \leq(3-4 \tau) / 7$, the second case appears if $(3-4 \tau) / 7<k \leq 3 / 7$, and the third case appears if $3 / 7<k$. When each firm chooses $d_{i}=1 / 2$ $(i=1,2)$, that is, $\gamma=0$, the first case appears if $k \leq(1-\tau) / 2$ and the third case appears if $(1-\tau) / 2<k$. We summarize the discussion in the following figure.

\footnotetext{
11 The calculus is highly complex but does not provide any economic information. The calculus is available from the authors on request.
} 
Figure 1 here

$* * * * * * * * * * * * * * * * * * * * * * * * *$

In Figure 1, (1), (2), and (3) refer to the equation number in equation (13) that applies to each region. For instance, suppose that the values of $k$ and $\tau$ are in region (e). When $d_{1}=d_{2}=0$, the third profit function (3) in equation (13) applies; when $d_{i}=0$ and $d_{j}=1 / 2$, the second profit function (2) in equation (13) applies; when $d_{1}=d_{2}=1 / 2$, the first profit function (1) in equation (13) applies. The payoff matrix is described in Table 1 (note that, $\gamma=1-d_{1}-d_{2}$ ).

$* * * * * * * * * * * * * * * * * * * * * * * * *$

Table 1 here

$* * * * * * * * * * * * * * * * * * * * * * * * *$

In region (e), both firms choose $d_{i}=1 / 2(i=1,2)$ in equilibrium if $k>15 \tau-3$, otherwise a firm chooses $d_{i}=0$ and another firm chooses $d_{j}=1 / 2(i=1,2, i \neq j)$ in equilibrium. We can apply this argument to all eight regions. Solving the payoff matrices for the eight regions, we have Proposition 2.

Proposition 2 When there are potential competitors for the upstream firms, if $F=0$ for any $d_{i}(i=1,2)$, depending on the exogenous values ( $k$ and $\left.\tau\right)$, the following outcome appears in equilibrium:

$$
\begin{aligned}
& d_{1}=d_{2}=1 / 2 \quad \text { if } \quad\left\{\begin{array}{l}
k \leq 33 / 109 \text { and } k \leq(6-19 \tau) / 6 \text { or } \\
33 / 109 \leq k \leq 12 / 31 \text { and } k \geq 15 \tau-3 \text { or } \\
12 / 31 \leq k,
\end{array}\right. \\
& d_{1}=0 \quad d_{2}=1 / 2 \quad \text { if } \quad 1 / 3 \leq k \leq 12 / 31 \text { and } k \leq 15 \tau-3, \\
& d_{1}=d_{2}=0 \quad \text { if } \quad k \leq 1 / 3 \text { and } k \geq 1-4 \tau .
\end{aligned}
$$

Proof: See Appendix.

The result is summarized in Figure 2. 
Figure 2 here

$* * * * * * * * * * * * * * * * * * * * * * * * *$

We now mention the intuition behind Proposition 2. In this setting, when a downstream firm enhances its degree of product differentiation (increases in $d_{i}$ ), it has a benefit and a cost. The benefit stems from the mitigation of competition between the downstream firms. The cost stems from the increase in its procurement cost if the competitive force of potential suppliers (their marginal costs are $k+\tau d_{i}$ ) is effective.

When $\tau$ is small, because the increase in $d_{i}$ is less effective in increasing the procurement cost $\left(k+\tau d_{i}\right)$, both downstream firms enhance the degree of product differentiation (see the left side in Figure 2).

When $k$ is small $(k \leq 1 / 3)$, there can be two equilibria if $\tau$ is in the medium range $((1-k) / 4 \leq \tau \leq 6(1-k) / 19$ if $k<33 / 109,(1-k) / 4 \leq \tau \leq(k+3) / 15$ if $33 / 109 \leq k<1 / 3)$. That is, strategic complementarity concerning the strategies of product differentiation exists (see the lower central area in Figure 2). When a downstream firm engages in product R\&D, this investment mitigates the competition between the downstream firms and enhances the profits of both. The increase in the profit of the downstream firm that does not engage in product $\mathrm{R} \& \mathrm{D}$ provides greater incentive to do so. On the other hand, when a downstream firm does not engage in product $\mathrm{R} \& \mathrm{D}$, the profit levels of both downstream firms are not large. Because of the limited profitability, product R\&D undertaken by a downstream firm does not compensate for the increase in its procurement cost $k+\tau d_{i}$. Therefore, if $\tau$ is in the medium range, two equilibrium outcomes can appear.

If $k$ is small and $\tau$ is sufficiently large, no downstream firm engages in product R\&D because the increase in the procurement cost $\left(k+\tau d_{i}\right)$ is significant (see the lower right side of Figure 2).

When $k$ is large, another interesting property can appear. Before we mention this property, 
we explain the relationship between wholesale prices and the value of $k$. In this model, $k=1 / 3$ is a critical value concerning the strategies of product differentiation. If $k$ is larger than $1 / 3$, potential suppliers do not function as a constraint on upstream firms when downstream firms do not engage in product $\mathrm{R} \& \mathrm{D}$ (that is, $d_{1}=d_{2}=0$ and $\gamma=1-d_{1}-d_{2}=1$ ). From the discussion of Section 3.1, when each upstream firm monopolistically supplies input, the wholesale price is $w_{i}=(2-\gamma) /(4-\gamma)=1 / 3$, which is smaller than $k$ if no downstream firm engages in product $\mathrm{R} \& \mathrm{D}\left(d_{1}=d_{2}=0\right)$.

When $k$ is larger than $1 / 3$ but is insufficiently large, if a downstream firm engages in product $R \& D$, the price set by the upstream firm that supplies to another downstream firm becomes binding because the increase in the degree of product differentiation enhances the incentive for the upstream firms to set their prices at higher levels. This is because $w_{i}$ in (6) is decreasing in $\gamma$. Because the price of the upstream firm that supplies the nonengaging downstream firm (call it firm $i$ ) is binding, the wholesale price for firm $i$ is positively correlated with the value of $d_{i}$. This feature of the wholesale price diminishes the incentive of firm $i$ to engage in product $\mathrm{R} \& \mathrm{D}$. Therefore, if $k$ is in the medium range $(1 / 3<k<12 / 31)$ and the value of $\tau$ is large $(\tau>(k+3) / 15)$, only one downstream firm engages in product $\mathrm{R} \& \mathrm{D}$ (see the upper right side of Figure 2). In this case, the profit of the engaging downstream firm is smaller than that of the nonengaging downstream firm.

\subsection{Positive investment cost}

From the discussion in the previous subsection, one may conclude that the degree of product differentiation is large even when $k$ is large. We now show that this conclusion is not always true.

Following the discussion of Lin and Saggi (2002), we now suppose that each downstream firm has to incur an investment cost for its product R\&D. We now specify the investment cost as $F\left(d_{i}\right)=c d_{i}^{2} / 2$. The marginal investment cost is $F^{\prime}\left(d_{i}\right)=c d_{i}$. 


\subsubsection{No potential supplier}

Substituting $\gamma=1-\left(d_{1}+d_{2}\right)$ into $\pi_{D 1}$ and $\pi_{D 2}$, we have:

$$
\pi_{D i}=\frac{4}{\left(3+d_{1}+d_{2}\right)^{2}\left(3-d_{1}-d_{2}\right)^{2}}-c d_{i}^{2} / 2, \quad(i=1,2)
$$

Differentiating $\pi_{D i}$ with respect to $d_{i}$, we have:

$$
\frac{\partial \pi_{D i}}{\partial d_{i}}=\frac{16\left(d_{1}+d_{2}\right)}{\left(3+d_{1}+d_{2}\right)^{3}\left(3-d_{1}-d_{2}\right)^{3}}-c d_{i} .
$$

We now provide three equilibrium outcomes that include minimum differentiation. Given that $d_{2}=0$, the marginal benefit from the investment (the partial derivative of $\Pi_{D 1} \equiv$ $\left.\pi_{D 1}+F\left(d_{1}\right)\right)$ is zero when $d_{1}=0$.

Figure 3 here

$* * * * * * * * * * * * * * * * * * * * * * * * *$

If $c$ is large enough, firm 1 also chooses $d_{1}=0$. We have the following proposition:

Proposition 3 Suppose that $F\left(d_{i}\right)=c d_{i}^{2} / 2$ for any $d_{i} \in[0,1 / 2](i=1,2) . d_{1}=d_{2}=0$ is an equilibrium outcome if $c>2272 / 99225 \simeq 0.02230$. The profits of the downstream and the upstream firms are:

$$
\pi_{D i}=\frac{4}{81}, \quad \pi_{U i}=\frac{2}{27}
$$

Proof: Given that $d_{2}=0$, differentiating $\pi_{D 1}$ with respect to $d_{1}$, we have,

$$
\left.\frac{\partial \pi_{D 1}}{\partial d_{1}}\right|_{d_{2}=0}=\frac{d_{1}\left(16-c\left(3-d_{1}\right)^{3}\left(3+d_{1}\right)^{3}\right)}{\left(3-d_{1}\right)^{3}\left(3+d_{1}\right)^{3}} .
$$

Because $\left(3-d_{1}\right)^{3}\left(3+d_{1}\right)^{3}$ is decreasing in $d_{1} \in[0,1 / 2]$, the partial derivative is (i) always positive or (ii) negative (resp. positive) if $d_{1}$ is small (resp. large) or (iii) always negative. Therefore, the net profit of firm 1 is maximized when $d_{1}=0$ or $d_{1}=1 / 2$. If $d_{1}=0$ maximizes 
the net profit, $d_{1}=d_{2}=0$ is an equilibrium outcome. When $d_{1}=0$, the net profit is $4 / 81$. When $d_{1}=1 / 2$, it is $(512-1225 c) / 9800$. A simple calculation $(4 / 81-(512-1225 c) / 9800)$ leads to this proposition.

Q.E.D.

Given that $d_{2}=1 / 2$, the marginal benefit from firm 1's investment is always positive (see Figure 4).

$* * * * * * * * * * * * * * * * * * * * * * * * *$

Figure 4 here

$* * * * * * * * * * * * * * * * * * * * * * * * *$

If $c$ is small enough, firm 1 also chooses $d_{1}=1 / 2$. We have the following proposition:

Proposition 4 Suppose that $F\left(d_{i}\right)=c d_{i}^{2} / 2$ for any $d_{i} \in[0,1 / 2](i=1,2) . d_{1}=d_{2}=1 / 2$ is an equilibrium outcome if $c<1 / 16 \simeq 0.0625$. The profits of the downstream and the upstream firms are:

$$
\pi_{D i}=\frac{1}{16}-\frac{c}{8}, \quad \pi_{U i}=\frac{1}{8} .
$$

Proof: Given that $d_{2}=1 / 2$, the partial derivative of $\Pi_{D 1}$ is

$$
\left.\frac{\partial \Pi_{D 1}}{\partial d_{1}}\right|_{d_{2}=1 / 2}=\frac{512\left(2 d_{1}+1\right)}{\left(7+2 d_{1}\right)^{3}\left(5-2 d_{1}\right)^{3}} .
$$

We now consider two functions.

$$
y_{1}=\frac{512(2 x+1)}{(7+2 x)^{3}(5-2 x)^{3}}, \quad y_{2}=c x .
$$

On the domain $[0,1 / 2]$, there is only one intersection of $y_{1}$ and $y_{2}$ if and only if $c \geq 1 / 16$ otherwise there is no intersection. In other words, for any $d_{1} \leq 1 / 2$, the partial derivative of $\Pi_{D 1}$ is larger than the marginal investment cost if and only if $c<1 / 16$. Therefore, $d_{1}=1 / 2$ is the optimal choice of firm 1 if $c \leq 1 / 16$.

Q.E.D.

The downstream firm's profit in which $d_{1}=d_{2}=1 / 2$ is larger than that in which $d_{1}=$ $d_{2}=0$ if and only if $c<17 / 162$. When $1 / 16<c<17 / 162$, maximum differentiation does not appear in equilibrium even though it is more profitable for the downstream firms. 
For intermediate values of $c$, there can be another symmetric equilibrium. We now suppose that $d_{1}=d_{2}=x$. The first-order condition of each firm is

$$
\frac{32 x}{(3+2 x)^{3}(3-2 x)^{3}}-c x=0 \quad \rightarrow \quad x^{e} \equiv \frac{1}{2} \sqrt{9-2\left(\frac{4}{c}\right)^{1 / 3}} .
$$

We can show that given $d_{j}=x^{e}$, the optimal choice of firm $i$ is $d_{i}=d_{j}=x^{e}$. In this case, the profits of the downstream and upstream firms are (see Figure 5):

$$
\begin{gathered}
\pi_{D i}=\frac{4}{\left(3+2 x^{e}\right)^{2}\left(3-2 x^{e}\right)^{2}}-\frac{c\left(x^{e}\right)^{2}}{2}, \quad \pi_{U i}=\frac{2\left(1+2 x^{e}\right)}{\left(3+2 x^{e}\right)^{2}\left(3-2 x^{e}\right)} . \\
* * * * * * * * * * * * * * * * * * * * * * * * * * * *
\end{gathered}
$$

Figure 5 here

$* * * * * * * * * * * * * * * * * * * * * * * * *$

Figure 6 provides an example in which multiple equilibria appear when $c$ is an intermediate value. In Figure 6 , given that $d_{j}=1 / 10$, the optimal choice of firm $i$ is also $d_{i}=1 / 10$. Moreover, given that $d_{j}=1 / 2$, the optimal choice of firm $i$ is also $d_{i}=1 / 2$. Both cases can appear as equilibrium outcomes. $x^{e}$ has an interesting property. As the coefficient of the marginal investment cost increases, $x^{e}$ increases.

\footnotetext{
$* * * * * * * * * * * * * * * * * * * * * * * * *$
}

Figure 6 here

$* * * * * * * * * * * * * * * * * * * * * * * * *$

Summary The above discussion is summarized in Figure 7.

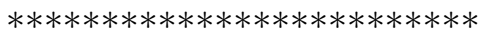

Figure 7 here

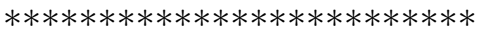

This result is in contrast with that in Brekke and Straume (2004). Using a Hotelling location model with upstream units, they show that the existence of those upstream units enhances 
the degree of product differentiation. ${ }^{12}$ In our setting, however, upstream units may diminish the degree of product differentiation. To prove that the statement is true, we reconsider the setting of Lin and Saggi (2002) (there is no upstream unit). In their model, the profit of each (downstream) firm and the marginal gain of product innovation are (we assume that the marginal cost is $h$ and the demand functions are the same ones discussed here):

$$
\pi_{i}=\frac{(1-h)^{2}}{\left(3-d_{i}-d_{j}\right)^{2}}, \quad \frac{\partial \pi_{i}}{\partial d_{i}}=\frac{2(1-h)^{2}}{\left(3-d_{i}-d_{j}\right)^{3}}, \quad i \neq j
$$

Because the marginal gain from the product innovation is positive for any $d_{j} \in[0,1 / 2]$, the equilibrium investment levels must be positive for any $c$ (note that the marginal cost of the investment is $c d_{i}$ ). Therefore, we find that if $c$ is large, the existence of upstream units diminishes the degree of product differentiation.

\subsubsection{Potential suppliers}

In this part, our main focus is the comparison between the case in which each upstream firm monopolistically supplies its input, and that in which it faces potential input suppliers. We only discuss region (a) in the previous subsection. That is, for any $d_{i} \in[0,1]$ the first equation in equation (13) applies. Substituting $\gamma=1-\left(d_{1}+d_{2}\right)$ into $\pi_{D 1}$ in equation (13), we have:

$$
\pi_{D 1}=\frac{\left(\left(1+d_{1}+d_{2}\right)(1-k)-\left(2 d_{1}-d_{2}+d_{1} d_{2}+d_{2}^{2}\right) \tau\right)^{2}}{\left(3-d_{1}-d_{2}\right)^{2}\left(1+d_{1}+d_{2}\right)^{2}}-c d_{1}^{2} / 2
$$

Differentiating $\pi_{D i}$ with respect to $d_{i}$, we have:

$$
\begin{aligned}
\frac{\partial \pi_{D 1}}{\partial d_{1}}= & \frac{2\left(\left(1+d_{1}+d_{2}\right)(1-k)-\left(2 d_{1}-d_{2}+d_{1} d_{2}+d_{2}^{2}\right) \tau\right)}{\left(3-d_{1}-d_{2}\right)^{3}\left(1+d_{1}+d_{2}\right)^{3}} \\
& \times\left(\left(1+d_{1}+d_{2}\right)^{2}(1-k)-\left(6+2 d_{1}^{2}+\left(9-2 d_{1}+d_{1}^{2}\right) d_{2}-2\left(2-d_{1}\right) d_{2}^{2}+d_{2}^{3}\right) \tau\right)-c d_{1} .
\end{aligned}
$$

\footnotetext{
${ }^{12}$ Note that, in their model, there is no investment cost for product innovation. Even though we introduce the product innovation costs discussed here into their model, the main result of their paper holds. That is, upstream units enhance the degree of product differentiation in Brekke and Straume (2004).
} 
Given that $d_{2}=0$, if the partial derivative is strictly positive, then the optimal value of $d_{1}$ is positive. Substituting $d_{2}=0$ into the partial derivative, we have:

$$
\begin{aligned}
&\left.\frac{\partial \pi_{D 1}}{\partial d_{1}}\right|_{d_{2}=0}=\frac{2\left(\left(1+d_{1}\right)(1-k)\right.}{27}\left.2 d_{1} \tau\right) \\
& \times\left((1-k+2 \tau) d_{1}^{2}+2(1-k) d_{1}+(1-k-6 \tau)\right)-c d_{1} .
\end{aligned}
$$

If $k+6 \tau<1$, when $d_{1}=0$, this is positive for any $c(>0)$. From the discussion, we have the following proposition:

Proposition 5 If $k+6 \tau<1$, the value of $\gamma$ is lower than 1 for any $c$.

The small values of $k$ and $\tau$ mean that upstream market competition is intense. In other words, if the procurement conditions for the downstream firms are preferable, the downstream firms tend to differentiate their products.

\section{Concluding remarks}

Using a simple product differentiation model with elastic demands, we investigate the relationship between differentiation strategies and vertical relations. Depending on the competitive structure in the upstream market, three differentiation patterns (maximum, minimum, and partial) can appear in equilibrium even though each downstream firm freely determines the degree of product differentiation. These results are somewhat different from those of previous studies (Brekke and Straume (2004) and Matsushima (2004, 2008)) that discuss how upstream units affect the differentiation strategies of downstream firms. Our model provides additional insights into the relationship between product differentiation and vertical relations.

We only consider the quantity-setting model. If we employed a price-setting model, the competition structure in the downstream market would be quite different. Although a pricesetting model is more complex than the quantity-setting model employed in this paper, investigating a price-setting model may be considered for future research. 


\section{References}

Ahmadjian, C. L. and J. R. Lincoln. 2001. Keiretsu, governance, and learning: Case studies in change from the Japanese automotive industry. Organization Science 12, pp. 683-701.

Aiura, H. and Y. Sato. 2008. Welfare properties of spatial competition with location dependent costs. Regional Science and Urban Economics 38, pp. 32-48.

Banerjee, S. and P. Lin. 2003. Downstream R\&D, raising rivals' costs, and input price contracts. International Journal of Industrial Organization 21, pp. 79-96.

Bárcena-Ruiz, J.C. and F.J. Casado-Izaga. 2008. Timing of endogenous bargaining over costs and firms' locations. Journal of Economics 95, pp. 149-166.

Beelaerts van Blokland, W.W.A., W.J.C. Verhagen, and S.C. Santema. 2008. The effects of co-innovation on the value-time curve: A quantitative study on product level. Journal of Business Market Management 2, pp. 5-24.

Belleflamme, P. and E. Toulemonde. 2003. Product differentiation in successive vertical oligopolies. Canadian Journal of Economics 36, pp. 523-545.

Bonaccorsi, A. and P. Giuri. 2001. The long-term evolution of vertically-related industries. International Journal of Industrial Organization 19, pp. 1053-83.

Buehler, S. and A. Schmutzler. 2008. Intimidating competitors-Endogenous vertical integration and downstream investment in successive oligopoly. International Journal of Industrial Organization 26, pp. 247-265.

Braun, S. 2008. Economic integration, process and product innovation, and relative skill demand. Review of International Economics 16, pp. 864-873.

Brekke, K. and O.R. Straume. 2004. Bilateral monopolies and location choice. Regional Science and Urban Economics 34, pp. 275-288. 
Brocas, I. 2003. Vertical integration and incentives to innovate. International Journal of Industrial Organization 21, pp. 457-488.

Cellini, R. and L. Lambertini. 2002. A differential game approach to investment in product differentiation. Journal of Economic Dynamics and Control 27, pp. 51-62.

d'Aspremont, C., J.J. Gabszewicz, and J.-F. Thisse. 1979. On Hotelling's 'stability in competition'. Econometrica 47, pp. 1145-1150.

Eaton, B. C. and N. Schmitt. 1994. Flexible manufacturing and market structure. American Economic Review 84, pp. 875-888.

Erkal, N. 2007. Buyer-supplier interaction, asset specificity, and product choice. International Journal of Industrial Organization 25, pp. 988-1010.

Esty, B. and P. Ghemawat. 2002. Airbus vs. Boeing in superjumbos: A case of failed preemption. HBS Strategy Unit Working Paper No. 02-061.

Hauser, J.R. and S.M. Shugan. 1983. Defensive marketing strategies. Marketing Science 2, pp. $319-60$.

Hotelling, H. 1929. Stability in competition. Economic Journal 39, pp. 41-57.

Ishii, A. 2004. Cooperative R\&D between vertically related firms with spillovers. International Journal of Industrial Organization 22, pp. 1213-1235.

Lambertini, L., S. Poddar, and D. Sasaki. 1998. Standardization and the stability of collusion. Economics Letters 58, pp. 303-310.

Lin, P. and K. Saggi. 2002. Product differentiation, process R\&D, and the nature of market competition. European Economic Review 46, pp. 201-211.

Matsushima, N. 2004. Technology of upstream firms and equilibrium product differentiation. International Journal of Industrial Organization 22, pp. 1091-1114. 
Matsushima, N. 2008. Vertical mergers and product differentiation. Journal of Industrial Economics, forthcoming.

Mantovani, A. 2006. Complementarity between product and process innovation in a monopoly setting. Economics of Innovation and New Technology 15, pp. 219-234.

Milliou, C. 2004. Vertical integration and R\&D information flow: is there a need for 'firewalls'? International Journal of Industrial Organization 22, pp. 25-43.

Nalebuff, B. 2002. Bundling and the GE-Honeywell Merger. Yale School of Management, Working Paper 22.

Norman, G. and J.-F. Thisse. 1999. Technology choice and market structure: strategic aspect of flexible manufacturing. Journal of Industrial Economics 47, pp. 345-372.

Pepall, L. and G. Norman. 2001. Product differentiation and upstream-downstream relations. Journal of Economics and Management Strategy 10, pp. 201-233.

Röller, L.-H. and M.M. Tombak. 1993. Competition and investment in flexible technologies. Management Science 39, pp. 107-114.

Rosenkranz, S. 2003. Simultaneous choice of process and product innovation when consumers have a preference for product variety. Journal of Economic Behavior and Organization 50, pp. $183-201$.

Sayman, S., S.J. Hoch, and J.S. Raju. 2002. Positioning of store brands. Marketing Science 21, pp. $378-397$.

Tombak, M.M. 2006. Strategic asymmetry. Journal of Economic Behavior and Organization 61, pp. 339-350.

Vandenbosch, M.B. and C.B. Weinberg. 1995. Product and price competition in a twodimensional vertical differentiation model. Marketing Science 14, pp. 224-249. 
Weiss, P. 2003. Adoption of product and process innovations in differentiated markets: The impact of competition. Review of Industrial Organization 23, pp. 301-314. 
Table 1: An example of a payoff matrix

\begin{tabular}{|l|cc|cc|}
\hline & \multicolumn{2}{|c|}{$d_{2}=0$} & \multicolumn{2}{c|}{$d_{2}=1 / 2$} \\
\hline$d_{1}=0$ & $4 / 81$ & $(3+k)^{2} / 225$ \\
& $4 / 81$ & & $(27-31 k)^{2} / 3600$ \\
\hline$d_{1}=1 / 2$ & $(3+k)^{2} / 225$ & $(27-31 k)^{2} / 3600$ & $(2-2 k-\tau)^{2} / 16$ \\
& \multicolumn{2}{|r|}{} & $(2-2 k-\tau)^{2} / 16$ \\
\hline
\end{tabular}




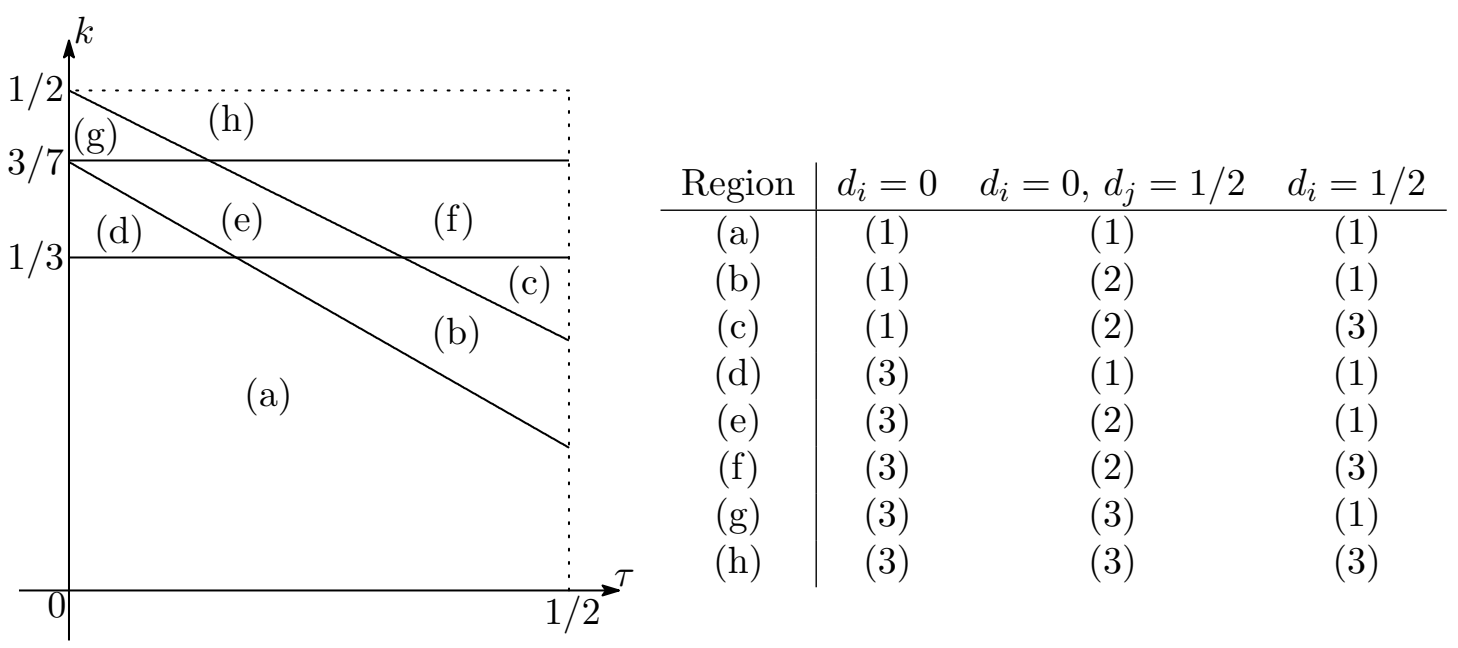

Figure 1: The relationship between $k, \tau$, and the profit functions in Eq. (13). 


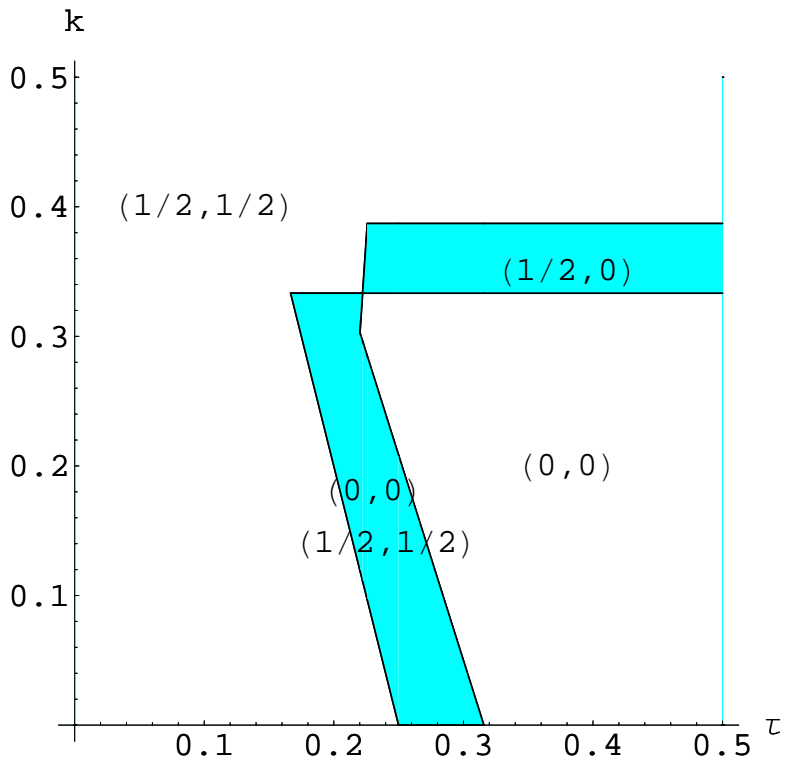

Figure 2: The equilibrium outcome. 


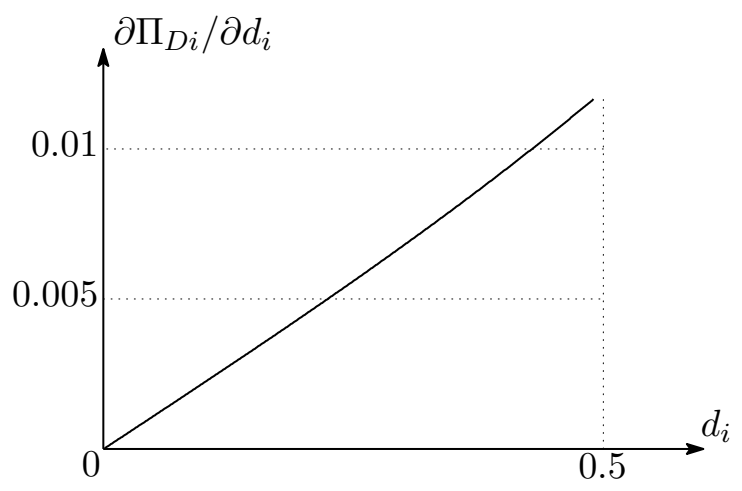

Figure 3: The marginal benefit from firm 1's investment $\left(d_{2}=0\right)$. 


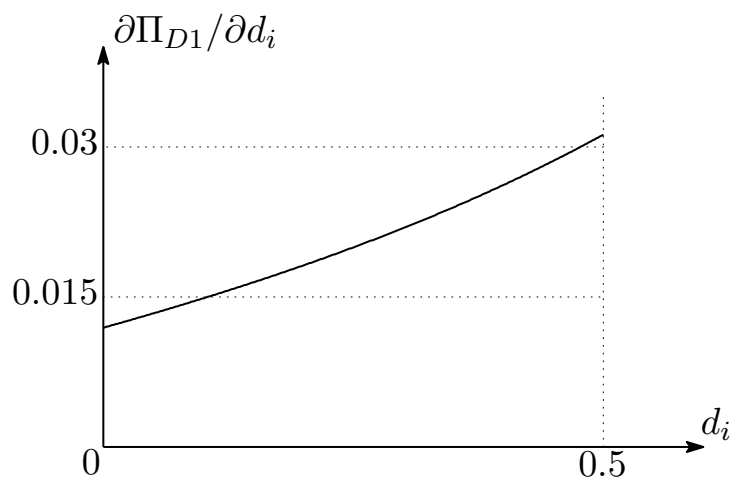

Figure 4: The partial derivative of $\pi_{D 1}\left(d_{2}=1 / 2\right)$. 


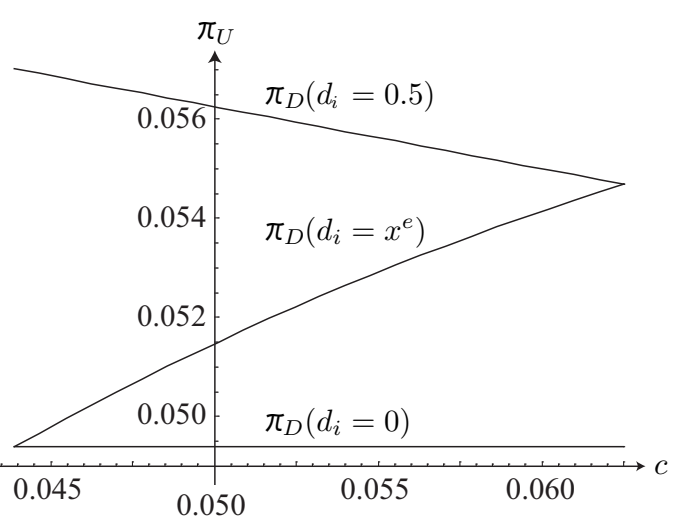

(downstream firm)

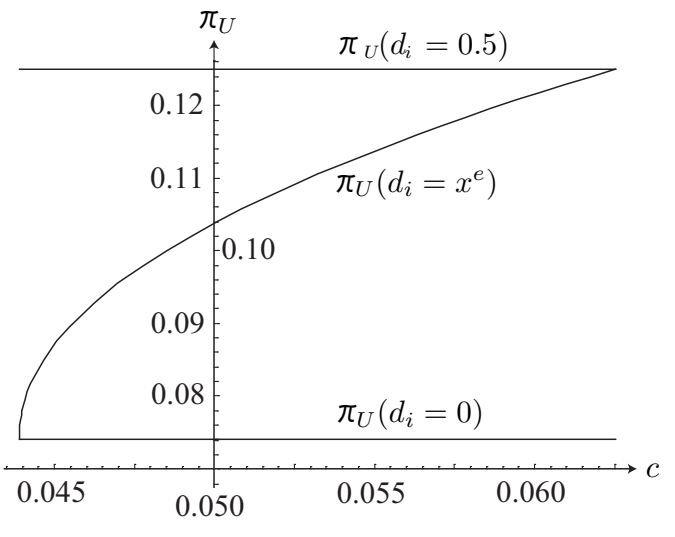

(upstream firm)

Figure 5: The profits of the downstream and the upstream firms. 


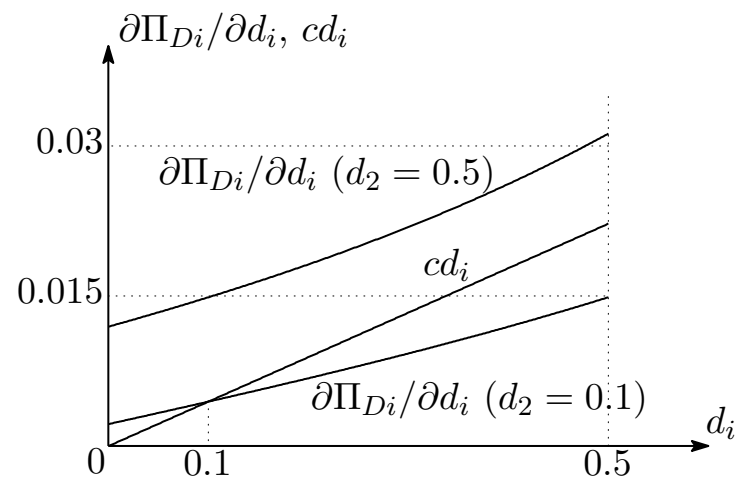

Figure 6: Complementarity between the choices of $d_{i}(c=15625 / 351232)$. 


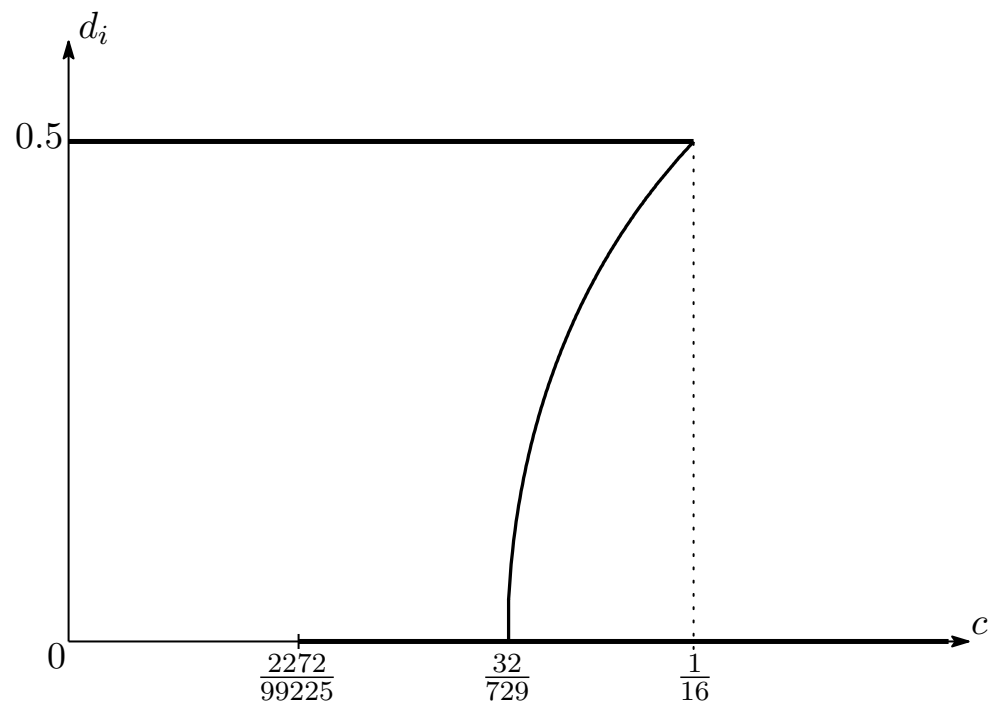

Figure 7: Multiple equilibria 


\section{Technical appendix}

Proof of Proposition 2 We must verify the equilibrium outcomes in the eight regions in Figure 1.

Region (a): The values of $k$ and $\tau$ are in region (a). For any $d_{i}(i=1,2)$, the first profit function (1) in equation (13) applies. The payoff matrix is described as follows (note that, $\gamma=1-d_{1}-d_{2}$ and we assume that $F\left(d_{i}\right)=0$ in this section):

\begin{tabular}{|l|cc|c|}
\hline & \multicolumn{2}{|c|}{$d_{2}=0$} & \multicolumn{1}{c|}{$d_{2}=1 / 2$} \\
\hline$d_{1}=0$ & $\frac{(1-k)^{2}}{9}$ & $\frac{(1-k)^{2}}{9}$ & $\frac{4(3-3 k-2 \tau)^{2}}{225}$ \\
\hline$d_{1}=1 / 2$ & $\frac{4(3-3 k-2 \tau)^{2}}{225}$ & $\frac{(6-6 k+\tau)^{2}}{225}$ & $\frac{(6-6 k+\tau)^{2}}{225}$ \\
\hline & & $\frac{(2-2 k-\tau)^{2}}{16}$ & \\
\hline
\end{tabular}

Given that $d_{2}=0$, firm 1 also chooses $d_{1}=0$ if

$$
\frac{(1-k)^{2}}{9}-\frac{4(3-3 k-2 \tau)^{2}}{225}=\frac{(k-(1-4 \tau))(11-11 k-4 \tau)}{225} \geq 0
$$

We find that both firms choose $d_{i}=0(i=1,2)$ in equilibrium if $k \geq 1-4 \tau$. Given that $d_{2}=1 / 2$, firm 1 also chooses $d_{1}=1 / 2$ if

$$
\frac{(2-2 k-\tau)^{2}}{16}-\frac{(6-6 k+\tau)^{2}}{225}=\frac{(6-19 \tau-6 k)(54-54 k-11 \tau)}{3600} \geq 0 .
$$

We find that both firms choose $d_{i}=1 / 2(i=1,2)$ in equilibrium if $k \leq(6-19 \tau) / 6$. From the discussion, we find that no case in which only one firm chooses $d_{i}=0$ appears in equilibrium because there is no $k$ that satisfies both $k \leq 1-4 \tau$ and $k \geq(6-19 \tau) / 6$.

Region (b): The values of $k$ and $\tau$ are in region (b). When $d_{1}=d_{2}=0$ or $d_{1}=d_{2}=1 / 2$, the first profit function (1) in equation (13) applies. When $d_{i}=0$ and $d_{j}=1 / 2(i=1,2$, $i \neq j$ ), the second profit function (2) in equation (13) applies. The payoff matrix is described as follows (note that, $\gamma=1-d_{1}-d_{2}$ and we assume that $F\left(d_{i}\right)=0$ in this section): 


\begin{tabular}{|l|cc|cc|}
\hline & \multicolumn{2}{|c|}{$d_{2}=0$} & \multicolumn{2}{c|}{$d_{2}=1 / 2$} \\
\hline$d_{1}=0$ & \multicolumn{2}{|c|}{$\frac{(1-k)^{2}}{9}$} & $\frac{(3+k)^{2}}{225}$ \\
\hline$d_{1}=1 / 2$ & $\frac{(1-k)^{2}}{9}$ & $\frac{(27-31 k)^{2}}{3600}$ & \\
& $\frac{(3+k)^{2}}{225}$ & $\frac{(27-31 k)^{2}}{3600}$ & $\frac{(2-2 k-\tau)^{2}}{16}$ & \\
\hline
\end{tabular}

Given that $d_{2}=0$, firm 1 also chooses $d_{1}=0$ if

$$
\frac{(1-k)^{2}}{9}-\frac{(3+k)^{2}}{225}=\frac{8(2-k)(1-3 k)}{225} \geq 0
$$

We find that both firms choose $d_{i}=0(i=1,2)$ in equilibrium for any $k$ and $\tau$. Given that $d_{2}=1 / 2$, firm 1 also chooses $d_{1}=1 / 2$ if

$$
\frac{(2-2 k-\tau)^{2}}{16}-\frac{(27-31 k)^{2}}{3600}=\frac{(3-15 \tau+k)(57-61 k-15 \tau)}{3600} \geq 0 .
$$

We find that both firms choose $d_{i}=1 / 2(i=1,2)$ in equilibrium if $k \geq 15 \tau-3$. Given that $d_{2}=0$, firm 1 chooses $d_{1}=1 / 2$ if

$$
\begin{aligned}
& \frac{(1-k)^{2}}{9}-\frac{(3+k)^{2}}{225}=\frac{8(2-k)(1-3 k)}{225} \leq 0 \\
& \frac{(2-2 k-\tau)^{2}}{16}-\frac{(27-31 k)^{2}}{3600}=\frac{(3-15 \tau+k)(57-61 k-15 \tau)}{3600} \leq 0 .
\end{aligned}
$$

We find that only one firm chooses $d_{i}=0$ in equilibrium if $k=1 / 3$ and $\tau \geq 2 / 9$.

Region (c): The values of $k$ and $\tau$ are in region (c). When $d_{1}=d_{2}=0$, the first profit function (1) in equation (13) applies. When $d_{i}=0$ and $d_{j}=1 / 2(i=1,2, i \neq j)$, the second profit function (2) in equation (13) applies. When $d_{1}=d_{2}=1 / 2$, the third profit function (3) in equation (13) applies. The payoff matrix is described as follows (note that, $\gamma=1-d_{1}-d_{2}$ and we assume that $F\left(d_{i}\right)=0$ in this section): 


\begin{tabular}{|c|cc|cc|}
\hline & \multicolumn{2}{|c|}{$d_{2}=0$} & \multicolumn{2}{c|}{$d_{2}=1 / 2$} \\
\hline$d_{1}=0$ & \multicolumn{2}{|c|}{$\frac{(1-k)^{2}}{9}$} & \multicolumn{2}{|c|}{$\frac{(3+k)^{2}}{225}$} \\
\hline$d_{1}=1 / 2$ & $\frac{(1-k)^{2}}{9}$ & $\frac{(27-31 k)^{2}}{3600}$ & \\
& $\frac{(3+k)^{2}}{225}$ & $\frac{(27-31 k)^{2}}{3600}$ & $\frac{1}{16}$ & \\
\hline
\end{tabular}

Given that $d_{2}=0$, firm 1 also chooses $d_{1}=0$ if

$$
\frac{(1-k)^{2}}{9}-\frac{(3+k)^{2}}{225}=\frac{8(2-k)(1-3 k)}{225} \geq 0 .
$$

We find that both firms choose $d_{i}=0(i=1,2)$ in equilibrium for any $k$ and $\tau$. Given that $d_{2}=1 / 2$, firm 1 also chooses $d_{1}=1 / 2$ if

$$
\frac{1}{16}-\frac{(27-31 k)^{2}}{3600}=-\frac{(42-31 k)(12-31 k)}{3600} \geq 0 .
$$

We find that no case in which both firms choose $d_{i}=1 / 2(i=1,2)$ appears in equilibrium. Given that $d_{2}=0$, firm 1 chooses $d_{1}=1 / 2$ if

$$
\begin{aligned}
& \frac{(1-k)^{2}}{9}-\frac{(3+k)^{2}}{225}=\frac{8(2-k)(1-3 k)}{225} \leq 0, \\
& \frac{1}{16}-\frac{(27-31 k)^{2}}{3600}=-\frac{(42-31 k)(12-31 k)}{3600} \leq 0 .
\end{aligned}
$$

We find that only one firm chooses $d_{i}=0$ in equilibrium if $k=1 / 3$.

Region (d): The values of $k$ and $\tau$ are in region (d). When $d_{1}=d_{2}=0$, the third profit function (3) in equation (13) applies. In the remaining cases, the first profit function (1) in equation (13) applies. The payoff matrix is described as follows (note that, $\gamma=1-d_{1}-d_{2}$ and we assume that $F\left(d_{i}\right)=0$ in this section): 


\begin{tabular}{|l|cc|c|}
\hline & \multicolumn{2}{|c|}{$d_{2}=0$} & \multicolumn{1}{c|}{$d_{2}=1 / 2$} \\
\hline$d_{1}=0$ & \multicolumn{2}{|c|}{$\frac{4}{81}$} & $\frac{4(3-3 k-2 \tau)^{2}}{225}$ \\
\hline$d_{1}=1 / 2$ & $\frac{4}{81}$ & $\frac{(6-6 k+\tau)^{2}}{225}$ & \\
\hline & $\frac{4(3-3 k-2 \tau)^{2}}{225}$ & $\frac{(2-2 k-\tau)^{2}}{16}$ & \\
\hline
\end{tabular}

Given that $d_{2}=0$, firm 1 also chooses $d_{1}=0$ if

$$
\frac{4}{81}-\frac{4(3-3 k-2 \tau)^{2}}{225}=-\frac{4(14-9 k-6 \tau)(4-9 k-6 \tau)}{2025} \geq 0 .
$$

Because $k \leq(3-4 \tau) / 7$ in this region, the above inequality does not hold. We find that no case in which both firms choose $d_{i}=0(i=1,2)$ appears in equilibrium. Given that $d_{2}=1 / 2$, firm 1 also chooses $d_{1}=1 / 2$ if

$$
\frac{(2-2 k-\tau)^{2}}{16}-\frac{(6-6 k+\tau)^{2}}{225}=\frac{(6-19 \tau-6 k)(54-54 k-11 \tau)}{3600} \geq 0 .
$$

We find that both firms choose $d_{i}=1 / 2(i=1,2)$ in equilibrium for any $k$ and $\tau$. Given that $d_{2}=0$, firm 1 chooses $d_{1}=1 / 2$ if

$$
\begin{aligned}
& \frac{4}{81}-\frac{4(3-3 k-2 \tau)^{2}}{225}=-\frac{4(14-9 k-6 \tau)(4-9 k-6 \tau)}{2025} \leq 0 \\
& \frac{(2-2 k-\tau)^{2}}{16}-\frac{(6-6 k+\tau)^{2}}{225}=\frac{(6-19 \tau-6 k)(54-54 k-11 \tau)}{3600} \leq 0
\end{aligned}
$$

We find that no case in which only one firm chooses $d_{i}=0$ appears in equilibrium.

Region (e): The values of $k$ and $\tau$ are in region (e). When $d_{1}=d_{2}=0$, the third profit function (3) in equation (13) applies. When $d_{i}=0$ and $d_{j}=1 / 2(i=1,2, i \neq j)$, the second profit function (2) in equation (13) applies. When $d_{1}=d_{2}=1 / 2$, the first profit function (1) in equation (13) applies. The payoff matrix is described as follows (note that, $\gamma=1-d_{1}-d_{2}$ and we assume that $F\left(d_{i}\right)=0$ in this section): 


\begin{tabular}{|l|cc|c|}
\hline & \multicolumn{2}{|c|}{$d_{2}=0$} & \multicolumn{2}{c|}{$d_{2}=1 / 2$} \\
\hline$d_{1}=0$ & \multicolumn{2}{|c|}{$\frac{4}{81}$} & $\frac{(3+k)^{2}}{225}$ \\
\hline$d_{1}=1 / 2$ & $\frac{4}{81}$ & $\frac{(27-31 k)^{2}}{3600}$ & \\
& $\frac{(3+k)^{2}}{225}$ & $\frac{(2-2 k-2 k-\tau)^{2}}{3600}$ & $\frac{(2-\tau)^{2}}{16}$ \\
\hline
\end{tabular}

Given that $d_{2}=0$, firm 1 also chooses $d_{1}=0$ if

$$
\frac{4}{81}-\frac{(3+k)^{2}}{225}=-\frac{(3 k-1)(19+3 k)}{2025} \geq 0
$$

We find that both firms choose $d_{i}=0(i=1,2)$ in equilibrium if $k=1 / 3$. Given that $d_{2}=1 / 2$, firm 1 also chooses $d_{1}=1 / 2$ if

$$
\frac{(2-2 k-\tau)^{2}}{16}-\frac{(27-31 k)^{2}}{3600}=\frac{(3-15 \tau+k)(57-61 k-15 \tau)}{3600} \geq 0 .
$$

We find that both firms choose $d_{i}=1 / 2(i=1,2)$ in equilibrium if $k \geq 15 \tau-3$. Given that $d_{2}=0$, firm 1 chooses $d_{1}=1 / 2$ if

$$
\begin{aligned}
& \frac{4}{81}-\frac{(3+k)^{2}}{225}=-\frac{(3 k-1)(19+3 k)}{2025} \leq 0, \\
& \frac{(2-2 k-\tau)^{2}}{16}-\frac{(27-31 k)^{2}}{3600}=\frac{(3-15 \tau+k)(57-61 k-15 \tau)}{3600} \leq 0 .
\end{aligned}
$$

We find that only one firm chooses $d_{i}=0$ in equilibrium if $k \leq 15 \tau-3$.

Region (f): The values of $k$ and $\tau$ are on region (f). When $d_{1}=d_{2}=0$ or $d_{1}=d_{2}=1 / 2$, the third profit function (3) in equation (13) applies. When $d_{i}=0$ and $d_{j}=1 / 2(i=1,2$, $i \neq j$ ), the second profit function (2) in equation (13) applies. The payoff matrix is described as follows (note that, $\gamma=1-d_{1}-d_{2}$ and we assume that $F\left(d_{i}\right)=0$ in this section): 


\begin{tabular}{|c|cc|cc|}
\hline & \multicolumn{2}{|c|}{$d_{2}=0$} & \multicolumn{2}{c|}{$d_{2}=1 / 2$} \\
\hline$d_{1}=0$ & \multicolumn{2}{|c|}{$\frac{4}{81}$} & $\frac{(3+k)^{2}}{225}$ \\
\hline$d_{1}=1 / 2$ & $\frac{4}{81}$ & $\frac{(27-31 k)^{2}}{3600}$ & \\
& $\frac{(3+k)^{2}}{225}$ & & $\frac{1}{16}$ & $\frac{1}{16}$ \\
\hline
\end{tabular}

Given that $d_{2}=0$, firm 1 also chooses $d_{1}=0$ if

$$
\frac{4}{81}-\frac{(3+k)^{2}}{225}=-\frac{(3 k-1)(19+3 k)}{2025} \geq 0
$$

We find that both firms choose $d_{i}=0(i=1,2)$ in equilibrium if $k=1 / 3$. Given that $d_{2}=1 / 2$, firm 1 also chooses $d_{1}=1 / 2$ if

$$
\frac{1}{16}-\frac{(27-31 k)^{2}}{3600}=\frac{(42-31 k)(31 k-12)}{3600} \geq 0
$$

We find that both firms choose $d_{i}=1 / 2(i=1,2)$ in equilibrium if $k \geq 12 / 31$. Given that $d_{2}=0$, firm 1 chooses $d_{1}=1 / 2$ if

$$
\begin{aligned}
& \frac{4}{81}-\frac{(3+k)^{2}}{225}=-\frac{(3 k-1)(19+3 k)}{2025} \leq 0, \\
& \frac{1}{16}-\frac{(27-31 k)^{2}}{3600}=\frac{(42-31 k)(31 k-12)}{3600} \leq 0 .
\end{aligned}
$$

We find that only one firm chooses $d_{i}=0$ in equilibrium if $1 / 3 \leq k \leq 12 / 31$.

Region (g): The values of $k$ and $\tau$ are in region (g). When $d_{1}=d_{2}=0$ or $d_{i}=0$ and $d_{j}=1 / 2(i=1,2, i \neq j)$, the third profit function (3) in equation (13) applies. When $d_{1}=d_{2}=1 / 2$, the first profit function (1) in equation (13) applies. The payoff matrix is described as follows (note that, $\gamma=1-d_{1}-d_{2}$ and we assume that $F\left(d_{i}\right)=0$ in this section): 


\begin{tabular}{|c|cc|cc|}
\hline & \multicolumn{2}{|c|}{$d_{2}=0$} & \multicolumn{2}{c|}{$d_{2}=1 / 2$} \\
\hline$d_{1}=0$ & & $\frac{4}{81}$ & $\frac{64}{1225}$ \\
& $\frac{4}{81}$ & & $\frac{64}{1225}$ & \\
\hline$d_{1}=1 / 2$ & & $\frac{64}{1225}$ & $\frac{(2-2 k-\tau)^{2}}{16}$ & \\
& $\frac{64}{1225}$ & $\frac{(2-2 k-\tau)^{2}}{16}$ & \\
\hline
\end{tabular}

Given that $d_{2}=0$, firm 1 also chooses $d_{1}=0$ if

$$
\frac{4}{81}-\frac{64}{1225}=-\frac{284}{99225} \geq 0
$$

We find that no case where both firms choose $d_{i}=0(i=1,2)$ appears in equilibrium. Given that $d_{2}=1 / 2$, firm 1 also chooses $d_{1}=1 / 2$ if

$$
\frac{(2-2 k-\tau)^{2}}{16}-\frac{64}{1225}=\frac{(102-70 k-35 \tau)(38-70 k-35 \tau)}{19600} \geq 0 .
$$

Because $k \leq(1-\tau) / 2$ in this region, the above inequality always holds. We find that both firms choose $d_{i}=1 / 2(i=1,2)$ in equilibrium for any $\tau$ and $k$. Given that $d_{2}=0$, firm 1 chooses $d_{1}=1 / 2$ if

$$
\begin{aligned}
& \frac{4}{81}-\frac{64}{1225}=-\frac{284}{99225} \leq 0, \\
& \frac{(2-2 k-\tau)^{2}}{16}-\frac{64}{1225}=\frac{(102-70 k-35 \tau)(38-70 k-35 \tau)}{19600} \leq 0 .
\end{aligned}
$$

We find that no case where only one firm chooses $d_{i}=0$ appears in equilibrium.

Region (h): The values of $k$ and $\tau$ are in region (h). For any $d_{i}$, the third profit function (3) in equation (13) applies. The payoff matrix is described as follows (note that, $\gamma=1-d_{1}-d_{2}$ and we assume that $F\left(d_{i}\right)=0$ in this section):

\begin{tabular}{|c|cc|cc|}
\hline & \multicolumn{2}{|c|}{$d_{2}=0$} & \multicolumn{2}{c|}{$d_{2}=1 / 2$} \\
\hline$d_{1}=0$ & \multicolumn{2}{|c|}{$4 / 81$} & \multicolumn{2}{c|}{$64 / 1225$} \\
& $4 / 81$ & & $64 / 1225$ \\
\hline$d_{1}=1 / 2$ & \multicolumn{2}{|c|}{$64 / 1225$} & $1 / 16$ & \\
& $64 / 1225$ & & \multicolumn{2}{|c}{$1 / 16$} \\
\hline
\end{tabular}


We find that both firms choose $d_{i}=1 / 2(i=1,2)$ in equilibrium for any $k$ and $\tau$. The other two cases do not appear in equilibrium. 